http://jmscr.igmpublication.org/home/

ISSN (e)-2347-176x ISSN (p) 2455-0450

crossref DOI: https://dx.doi.org/10.18535/jmscr/v9i6.45

Journal Of Medical Science And Clinical Research

\title{
Depressive symptoms in patients of schizophrenia in state mental health hospital
}

\author{
Authors \\ Abhilaksh Kango ${ }^{*}$, Anukriti Singh ${ }^{2}$ \\ ${ }^{1}$ Psychiatrist, Himachal Hospital of Mental Health and Rehabilitation, Shimla (HP) \\ ${ }^{2}$ Medical Officer, IGMC, Shimla (HP) \\ *Corresponding Author \\ Dr Abhilaksh Kango
}

Psychiatrist, Himachal Hospital of Mental Health and Rehabilitation, Shimla (HP), 171005, India

Abstract
Aim: To study prevalence of depressive symptoms in schizophrenia patients in HHMH \& R, Shimla.
Material and Methods: A cross-sectional observation was done in schizophrenia patients admitted in
our hospital with diagnosis of schizophrenia. After informed consent sociodemographic information and
clinical characteristics were collected from patients and attendants.
Results: Mean age of participants was around 37 years and most were male and single. Olanzapine was
most common prescribed drug second most common was haloperidol. Depressive symptoms were
reported by $54 \%$ of participants out of which $26 \%$ participants had clinically significant depression as
per CDSS.
Conclusion: In schizophrenia it is difficult to distinguish true negative and depressive symptoms. But
over 50\% of patients have depressive symptoms which needs proper assessment and timely measures to
prevent suicides and improve quality of life of patients.
Keywords: Calgary depression scale (CDSS), Positive and negative syndrome scale (PANSS).

\section{Introduction}

In schizophrenia negative symptoms may cause decrease in normal emotions and functions which also can be due to depression ${ }^{[1]}$. Depressive symptoms are frequently seen in schizophrenia patients, in past studies prevalence is seen between $10-75 \%^{[2,3]}$. Suicidal thoughts are also common in these patients ${ }^{[4,5]}$ and as many as 2$13 \%$ of them ultimately attempt suicide and majority of them report depressive symptoms during the course of illness, specifically helplessness and feeling worthless ${ }^{[6,7]}$. These above factors warrant recognising and treating depression one of most important but overlooked facet in management of schizophrenia.Due to difficulty in delineating the negative symptoms and depressive symptoms the prevalence rates of depression among schizophrenics vary widely.In literature it is said that attributing symptoms to these conditions should be guided by the nature of presenting symptomatology, in which sadness predominate in depression while apathy in schizophrenia $^{[8]}$. Our study looks into depressive symptoms in schizophrenia patients and emphasise that we should not overlook depressive symptoms considering them as negative symptoms. 


\section{Material and Methods}

In months of January and February 2021 crosssectional observation was done in $\mathrm{HHMH} \& \mathrm{R}$ Shimla after proper informed consent. All patients admitted in our hospital during that period with diagnosis of schizophrenia were included in study. We confirmed diagnosis as per MINI-PLUS and patient meeting diagnosis of schizophrenia were included in study. Socio-demographic data was obtained and psychopathology and depressive symptoms were rated on PANSS and CDSS scales.

\section{Statistical Analysis}

The collected data was analysed using SPSS software. For continuous variables mean and standard deviation were used and for categorical variables frequencies were used.

Table 1: Socio-demographic profile of patients

\begin{tabular}{|l|c|}
\hline Variables & $\begin{array}{c}\text { Participants } \\
\text { N=47 } \\
\text { Mean (SD)/ } \\
\text { Frequency (\%) }\end{array}$ \\
\hline Age in years & $37.28(11)$ \\
\hline Gender & $34(73.9 \%)$ \\
Male & $12(26.1 \%)$ \\
Female & $35(76.1 \%)$ \\
\hline Marital status & $11(23.9 \%)$ \\
Single & $17(37.0 \%)$ \\
Married & $12(21.7 \%)$ \\
\hline Medication & $17(37.0 \%)$ \\
Olanzapine & \\
Haloperidol & $15(32.6 \%)$ \\
Others & $31(67.4 \%)$ \\
\hline Co-morbidity & \\
Yes & $23(50 \%)$ \\
No & $23(50 \%)$ \\
\hline Substance use history & \\
Yes & \\
No &
\end{tabular}

Table 2: Clinical profile of patients

\begin{tabular}{|l|c|}
\hline Variables & $\begin{array}{c}\text { Participants } \\
\text { N=47 } \\
\text { Mean (SD)/ } \\
\text { Frequency (\%) }\end{array}$ \\
\hline PANSS & $14.89(6.87)$ \\
\hline Positive subscale score & $18.08(7.89)$ \\
\hline Negative subscale score & $28.34(9.70)$ \\
\hline $\begin{array}{l}\text { General psychopathology } \\
\text { subscale score }\end{array}$ & $6.60(2.48)$ \\
\hline PANSS Depression subscale & $58.32(21.93)$ \\
\hline Total PANSS Score & $4.28(3.61)$ \\
\hline CDSS & $12(26.1 \%)$ \\
\hline CDSS total score \\
\hline Depression as per CDSS $(\geq 6)$ &
\end{tabular}




\section{Results}

Mean age of participants was 37.28 years and most of them were males and single (76.1\%). Olanzapine was most commonly prescribed drug second most common was Haloperidol. Substance use was found in around half of participants in which tobacco was commonest. Co-morbidities were also fairly common. Hypertension was found in $15 \%$ participants and diabetes was present in $8.7 \%$ of participants.\{Table 1$\}$

In clinical profile on PANSS participants scored higher on general psychopathology subscale (28.3) followed by Negative symptom subscale (18.08). On CDSS 25 participants (54\%) reported depressive symptoms out of which 12 participants (26\%) had clinically significant depression (Total CDSS score $\geq 6$ ). $\{$ Table 2$\}$

\section{Discussion}

Our study demonstrates over $50 \%$ incidence of depressive symptomatology in schizophrenia patients. Whereas in other study the incidence was around $13 \%$ in schizophrenia patients [9]. Which can be explained by use of different instrument (BDI-II) in that study to study the prevalence of depressive symptoms. Keeping away the differences in percentage of depression prevalence among schizophrenia patients, that can be explained as different population and methodologies were used, there is a agreement that depression is a common co-morbidityin schizophrenia leading to relapses. In a study they have emphasized that acute phase of schizophrenia can be preceded by depression ${ }^{[3]}$. Others have reported that around $60 \%$ of patients and $75 \%$ of their caregivers reported depressive symptoms as a factor leading to relapse ${ }^{[10]}$. Depression can be seen in all phases of illness ${ }^{[11]}$ and affects the course of the illness, causing aggravations, which leads to modifications in management ${ }^{[8]}$, and is also a main risk factor for suicidal attempts. In literature it has been seen that around $10 \%$ of schizophrenia patients commit suicide, more significantly majority of them had depressive episodes in past or had shown depressive symptoms during their visits to psychiatrists $^{[3]}$. At times depressive symptoms may mimic or overlooked as negative symptoms. It is tough to delineate them and one has to be very diligent enough while assessing patients with schizophrenia with predominant negative symptoms. If these go untreated, they can lead to a relapse or even suicide among patients. Depression in schizophrenia lead to difficulties in adjustment during rehabilitation, like unemployment, decreased activity and satisfaction, suicidal thoughts, leading to rehospitalizations. In our study it is emphasised that thorough psychological evaluation can lead to picking up of patients who are at risk of having depression which will allow clinicians to take timely measures to prevent same.

\section{Conclusion}

Depressive symptoms in schizophrenia are fairly common and commonly mistaken or overlooked as negative symptoms. Over $50 \%$ of patients had depressive symptoms out of which $26 \%$ patients had clinically significant depression including suicidal ideations. These can lead to repeated exacerbations, hospitalizations and even suicide if overlooked. So clinicians should be keen to pick depressive symptoms and proper psychological assessment should be done to ascertain the diagnosis and timely measures should be taken.

\section{References}

1. Pokorski M, Warzecha a. Depression and religiosity in older age. Eur J Med Res. 2011; 16: 1-6.

2. Barnes tR, curson Da, Liddle PF, Patel M. the nature and prevalence of depression in chronic schizophrenic inpatients.Br J Psychiatry. 1989; 154: 486-91.

3. Mulholland c, cooper s. the symptoms of depression in schizophrenia and its management. adv Psychiatr treat.2000; 6: 169-77.

4. Caldwell cB, Gottesman II. schizophrenics kill themselves too: a review of risk factors 
for suicide. Schizophr Bull. 1990; 16: 57189.

5. Bartels sJ, Drake RE, McHugo GJ. alcohol abuse, depression and suicidal behavior in schizophrenia. Am J Psychiatry. 1992; 149: 394-5.

6. Drake RE, cotton PG. Depression, hopelessness and suicide in chronic schizophrenia. Br J Psychiatry. 1986; 148:554-9.

7. Bandelow B, Muller P, Gaebel WE. Depressive syndromes in schizophrenic patients after discharge from hospital. Eur arch Psychiatry clin neurosci. 1991; 240:113-20.

8. Siris SG, Bench c. Depression and schizophrenia. In: Hirsch SR, Weinberger DR (eds.), schizophrenia. Black-well Science: oxford, 2003.

9. Baynes D, Mulholland c, cooper sJ, Montgomery Rc, MacFlynn G, Lynch G, Kelly c, King DJ. Depressive symptoms in stable chronic schizophrenia: Prevalence and relationship to psychopathology and treatment. Schizophr Res. 2000; 45: 47-56.

10. Herz M, Melville c. Relapse in schizophrenia. am J Psychiatry. 1980; 137: 801-5.

11. Emsley $\mathrm{Ra}$, oosthuizen PP, Joubert $\mathrm{aF}$, Roberts Mc,stein DJ. Depressive and anxiety symptoms in patients with schizophrenia and schizophreniform disorder. J clin Psychiatry. 1999; 60: 74751. 